\title{
Das Praxishandbuch für young-dentists!
}

$\mathrm{B}$ ereits seit 1993 ist das Praxishandbuch des Freien Verbandes Deutscher Zahnärzte (FVDZ) treuer Begleiter für ca. 6000 Abonnenten. Mit Informationen, Tipps und Ratschlägen zu Abrechnungsfragen, betriebswirtschaftlichen und rechtlichen Themen bietet das Praxishandbuch gerade auch für die junge Praxis eine solide Grundlage für die Organisation des freiberuflichen Unternehmens Zahnarztpraxis. Die Bewertung aktueller gesundheitspolitischer Entwicklungen in ihren Auswirkungen auf den Praxisablauf kommt dabei ebenfalls nicht zu kurz.

Im Zeitalter elektronischer Wissensverarbeitung geht auch das Praxishandbuch moderne Wege. Es gibt jetzt zusätzlich eine Internet-Version des Nachschlagewerks.

Der Inhalt steht aufbereitet im Internet zur Verfügung. Durch eine Menüführung lassen sich alle Kapitel aufrufen und im Netz lesen. Bei Bedarf können die Seiten auch ausgedruckt werden. young-dentists erhalten die Web-Version ohne Einrichtungskosten und sparen damit $30 €$ (FVDZ-Mitglieder) bzw. $60 €$ (Nicht-Mitglieder).

Nutzen Sie das Praxishandbuch zu Ihrem Vorteil!

Die Ausgaben für das Praxishandbuch können Sie übrigens in voller Höhe steuerlich geltend machen.

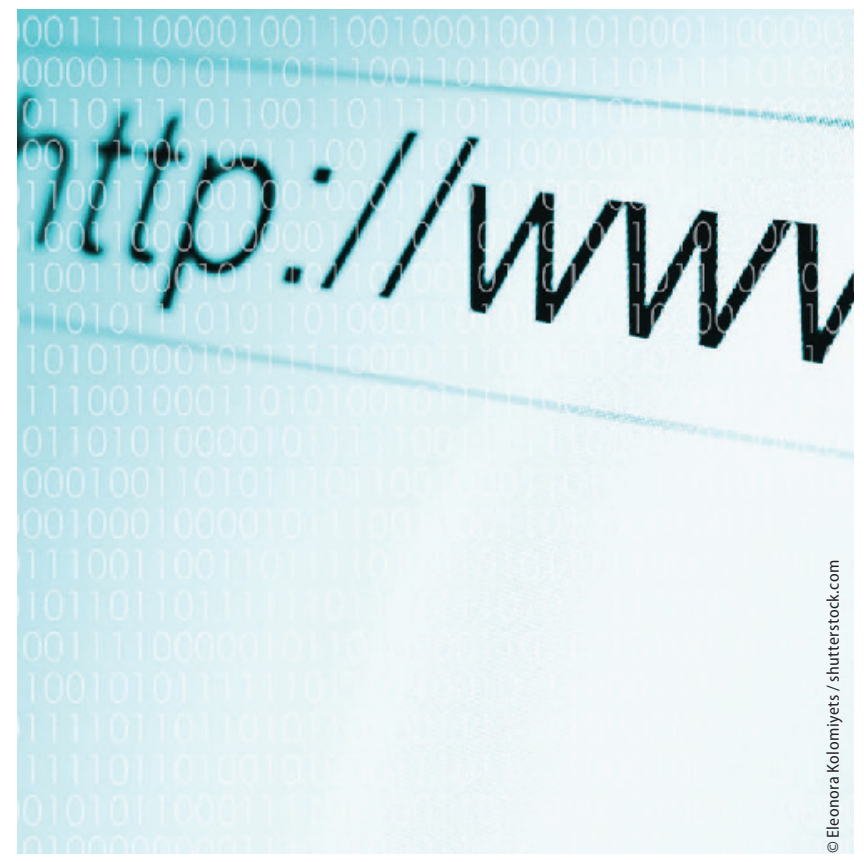

\section{Jetzt auch online!}

\author{
Als yd ${ }^{2}$-Mitglied bestelle ich die Web-Version des Praxishandbuchs zum Preis von: \\ - 36 € Jahresabo für FVDZ-Mitglieder \\ - $48 €$ Jahresabo für Nichtmitglieder
}

Das Abonnement hat eine Mindestlaufzeit von 1 Jahr.

yd2-Mitgliedsnummer

Vorname

Straße

Unterschrift
FVDZ Mitgliedsnummer

Nachname
PLZlOrt

FAX 0228/8551162 // www.young-dentists.de 